\title{
The Clinician Investigator Program at the University of Ottawa
}

\author{
Jonathan B. Angel, $\mathrm{MD}^{1,2}$ \\ ${ }^{1}$ Director, Clinician Investigator Program and Professor of Medicine, University of Ottawa \\ ${ }^{2}$ Senior Scientist, Ottawa Hospital Research Institute
}

\section{A B STRACT}

Clinician investigators play a critical role in developing new approaches and improving upon existing approaches to medical care, ultimately resulting in improved health of Canadians. Such individuals are uniquely suited to conduct research that addresses clinical observations as well as translates research findings into novel approaches to disease management and prevention. The need for such individuals has long been recognized and in 1995, the Royal College of Physician and Surgeons of Canada (RCPSC) developed the first formal training program in the country to help support the development of clinician investigators. Since its inception, over 200 trainees have completed the RCPSC Clinician Investigator Program (CIP), the details of which are communicated in a review by Cathy Hayward et al. [1] in Clinical and Investigative Medicine. Currently, the CIP is active at 15 (almost all) medical schools across the country.

Dr. Andrew Badley, a clinician scientist in the Division of Infectious Disease, led the development of the application for the CIP at the University of Ottawa ( $U$ of O), which was ultimately approved in 2002. In 2003 Jonathan Angel became the Director of the CIP at U of $\mathrm{O}$ and in 2004, the first trainee was accepted into the program. Since then, approximately 40 trainees have enrolled in the CIP, and as of April 2014, 25 trainees have completed the program. While a few of the recent trainees have resumed clinical training following their research activities, the majority of the graduates $(n=14)$ have gone on to assume academic positions at the University of Ottawa and elsewhere.

\section{RÉSUMÉ}

Les cliniciens-chercheurs jouent un rôle clé dans le développement de nouvelles méthodes et dans l'amélioration des méthodes existantes dans les soins médicaux. Le but est, ultimement, d'améliorer la santé des Canadiens et Canadiennes. Ces personnes sont bien placées pour mener des projets de recherche qui portent sur des observations cliniques et qui traduisent les résultats de recherche en approches novatrices pour la prévention et la prise en charge des maladies. Le besoin pour ces professionnels est reconnu depuis longtemps. En 1995, le Collège royal des médecins et chirurgiens du Canada (CRMCC) a créé le premier programme officiel pour appuyer le perfectionnement des cliniciens-chercheurs. Depuis sa création, plus de 200 personnes ont complété le Programme de cliniciens-chercheurs (PCC) du CRMCC. Une revue du programme a été publiée par Cathy Hayward et coll., dans la revue Clinical and Investigative Medicine. Actuellement, le PCC est offert dans 15 facultés de médecine au Canada, soit presque la totalité d'entre elles.

Dr Andrew Badley, un clinicien-scientifique de la Division des maladies infectieuses, a mené l'intégration du PCC à l'Université d'Ottawa, programme qui a été approuvé ultimement en 2002. En 2003, Jonathan Angel est devenu le directeur du PCC de l'Université d'Ottawa et, en 2004, le premier stagiaire du programme était admis. Depuis cette date, environ 40 stagiaires se sont inscrits au PCC et, en avril 2014, 25 d'entre eux avaient terminé le programme. Bien que quelques-uns des plus récents stagiaires aient repris leur formation clinique après avoir achevé leur recherche, la majorité des finissants $(n=14)$ ont accepté des fonctions universitaires à l'Université d’Ottawa ou ailleurs.

\section{DESCRIPTION OF THE CIP PROGRAM}

As clearly outlined in the RCPSC Specific Standards of Accreditation [2]:

"The major goal of the Clinician Investigator Program (CIP) is to assist in the career development of clinician investigators in Canada. The training involves a minimum of two years of research intensive training that involves enrolment in a graduate degree program (graduate stream), to complete a thesis or equivalent, or in a postdoctoral fellowship program if the resident already has a graduate degree (postdoctoral stream). For the purpose of this program, health research includes not only the traditional areas of laboratory and clinical biomedical research, but also such fields as economics and management, and social, behavioural, and information sciences as they apply to health and disease."

In addition to facilitating access to dedicated research activities, the CIP provides additional educational activities for trainees, another benefit of enrolment in this program. An important part of the CIP curriculum is a seminar series covering topics that are not otherwise formally taught. Examples of seminar topics include: submitting a proposal to the Research Ethics Board, understanding intellectual property, negotiating your first 


\section{Commentary}

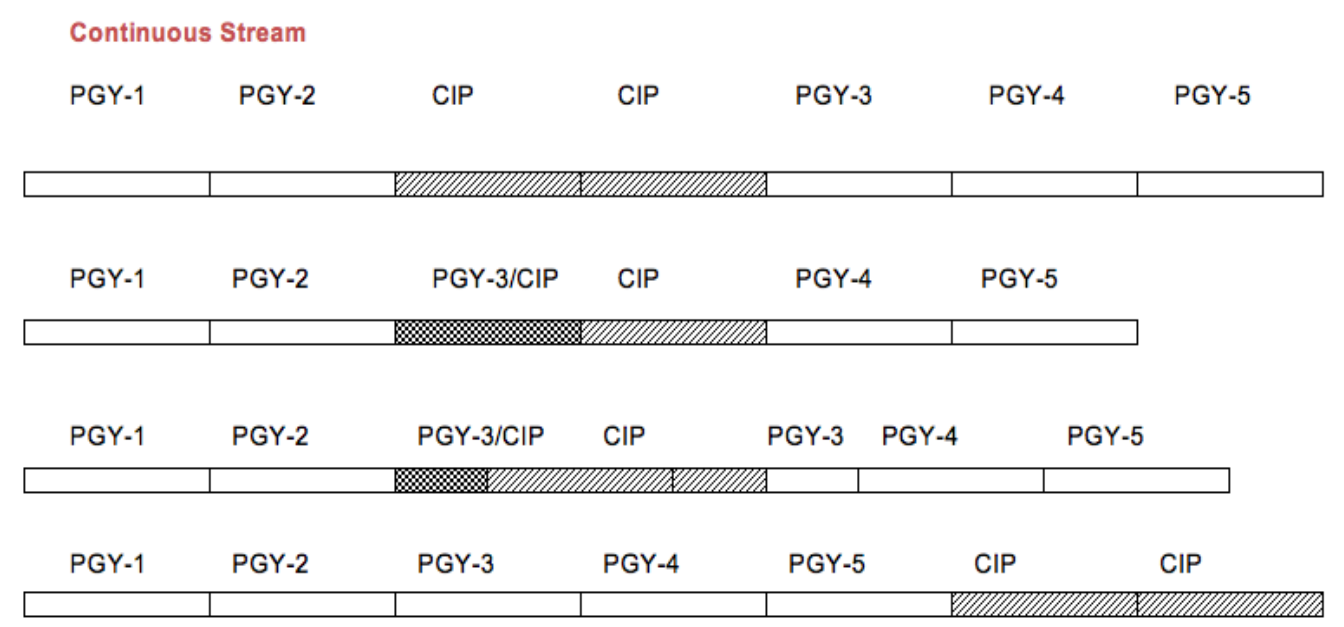

\begin{tabular}{|c|c|c|c|c|c|c|c|c|}
\hline$P G Y=1$ & PGY-2 & CIP & $P G Y-3$ & CIP & $P G Y-3$ & $\mathrm{CIP}$ & $P G Y-4$ & PGY-5 \\
\hline
\end{tabular}

Legend

Figure 1. Examples of two year Continuous and Fractionated Stream CIP training during a typical 5 year residency.

\begin{tabular}{ll}
\hline & Core clinical training \\
& CIP research training \\
& CIP training during elective/research component of core training program
\end{tabular}

Figure 1. Schematic of continuous and fractionated training pathway in the CIP

contract, and establishing a career as a clinician investigator. An additional significant benefit of these seminars is that they provide an environment for clinician researchers-in-training to gather and share ideas and discuss issues that are specific to them.

The CIP has been designed to accommodate trainees with varying degrees of previous research experience. Those that have little research experience must be registered in the Faculty of Graduate and Post-Doctoral Studies and co-enrolled in a thesis-based graduate program. At the University of Ottawa, most trainees will do an MSc or PhD in the Department of Epidemiology, Biochemistry, Microbiology and Immunology or Cellular and Molecular Medicine. However, training opportunities are not limited to these Departments, or even the Faculty of Medicine for that matter. Past CIP trainees, for example, have also pursued graduate degrees in the Faculty of Education and in the Telfer School of Management. Enrolment in these graduate programs provides the structure and supervision required to achieve a productive, valuable research experience. For trainees that already have a relevant graduate degree, the CIP offers a post-graduate stream. These select trainees must establish a Research Advisory Committee (analogous to a Thesis Advisory Committee that is required within graduate training) and establish clear research objectives and milestones that must be met for successful completion of their training.

At the University of Ottawa, there are two potential pathways for CIP training: The Continuous Training pathway and the Fractionated Training pathway (Figure 1). The vast majority of trainees undertake the Continuous Training pathway, which involves a minimum of 24 months of continuous, intensive research training. The Fractionated Training pathway, on the other hand, is intended to allow for a distribution of a minimum 24 months of research in periods of three months or longer, with at least one year of continuous research training. The Fractionated Training option was developed for individuals who wish to pursue research that requires several years to plan a research project, obtain research ethics board approval, and complete the project, which may involve patient recruitment. This pathway is particularly suitable for clinical epidemiology research, where intensive research activities may be separated by periods 
of waiting or inactivity.

The CIP is also designed to accommodate trainees at any stage during or following their clinical training. The ideal time for research training is highly dependant on the individual trainee and their career goals. Coordinating 24 months of dedicated research time with clinical training requires advanced planning and coordination with clinical Program Directors and Division Heads. Because of this, trainees are typically first enrolled in, or are concurrently completing, a Royal College residency at the University of Ottawa before they are able to pursue CIP training. This coordination must also ensure that while CIP trainees are committed to spend the majority of their time engaging in research activities (a minimum $80 \%$ of time), they are also maintaining/developing clinical expertise and dealing with aspects of time management, which are important skills for the development of clinician researchers.

\section{SUMMARY}

Since the introduction of the CIP in Ottawa, recognition of its importance has grown, as has the demand for enrolment in the program. In recognition of this, support from the office of Postgraduate Medical Education has steadily increased and, importantly, the Ontario Ministry of Health and Long-Term Care now provides dedicated funding for a number of trainees in this program. Both of these factors contribute to the ongoing and future success of this important program.

\section{REFERENCES}

1. http://www.royalcollege.ca/cs/groups/public/documents/document/ y2vk/mdaw/ edisp/tztest3rcpsced000750.pdf (accessed March 27, 2014)

2. Hayward CP, Danoff D, Kennedy M, Lee AC, Brzezina S, Bond U. Clinician investigator training in Canada: a review. Clin Invest Med 2011;34(4):E192.

Keywords: Royal College of Physicians and Surgeons of Canada, Research, Residency, Clinician Scientist, Competency-Based, Inter-professional 